\title{
Semi-clathrate hydrate phase stability conditions for methane + TetraButylAmmonium Bromide (TBAB)/ TetraButylAmmonium Acetate (TBAA) + water system: Experimental measurements and thermodynamic modeling
}

\author{
Hamideh Irannezhad ${ }^{1}$, Jafar Javanmardi ${ }^{1, a,{ }^{*}}$, Ali Rasoolzadeh ${ }^{2}$ (D), Khayyam Mehrabi ${ }^{1}$ (D), and Amir H. Mohammadi ${ }^{3, a,{ }^{*}}$ \\ ${ }^{1}$ Department of Chemical, Petroleum and Gas Engineering, Shiraz University of Technology, 7155713876 Shiraz, Iran \\ ${ }^{2}$ Department of Natural Gas Engineering, School of Chemical and Petroleum Engineering, Shiraz University, 7194684334 Shiraz, Iran \\ ${ }^{3}$ Discipline of Chemical Engineering, School of Engineering, University of KwaZulu-Natal, Howard College Campus, \\ King George V Avenue, 4041 Durban, South Africa
}

Received: 25 May 2021 / Accepted: 28 September 2021

\begin{abstract}
One of the promising applications of clathrate/gas hydrates is the transport and storage of natural gas. Semi-clathrate hydrates have received more attention due to milder pressure/temperature stability conditions compared to ordinary clathrate hydrates. The most commonly reported semi-clathrate hydrates are formed from a combination of gas + water + quaternary ammonium salts. In this work, a total of 53 equilibrium data for semi-clathrate hydrates of methane + TetraButylAmmonium Bromide (TBAB)/ TetraButylAmmonium Acetate (TBAA) aqueous solutions were experimentally measured. For TBAB, three concentrations including 0.0350, 0.0490, and 0.1500 mass fractions were used. For TBAA, a solution with a 0.0990 mass fraction was used. Additionally, the modified Chen-Guo model was applied to calculate the hydrate phase equilibrium conditions of methane + TBAB/TBAA aqueous solutions. The model can accurately calculate the aforementioned semi-clathrate hydrate phase equilibrium conditions with the Average Absolute Deviations $\left((\mathrm{AAD})_{T}\right.$ and $\left.(\mathrm{AAD})_{P}\right)$ of $0.1 \mathrm{~K}$ and $0.08 \mathrm{MPa}$, respectively. The temperature increments for $0.0350,0.0490$, and 0.1500 mass fractions of TBAB are 7.7, 9.4, and $13.5 \mathrm{~K}$, respectively. This value for 0.0990 mass fraction of TBAA is $6.2 \mathrm{~K}$. Therefore, it is concluded that TBAB is a stronger hydrate promoter compared to TBAA.
\end{abstract}

\section{Nomenclature}

$\lambda_{2} \quad$ The number of guest molecules per water molecule

G The guest species

$f \quad$ The fugacity of the guest species

$f^{0} \quad$ The fugacity of the guest molecule in equilibrium with the unfilled basic hydrate

$\theta \quad$ The fraction of the linked cavities occupied by the guest molecules

$\alpha \quad$ Fractional coefficient

$\lambda_{1} \quad$ The number of linked cavities per water molecule

$C \quad$ The Langmuir constant

$X, Y, Z$ Antoine constants for calculating the Langmuir constant

\footnotetext{
* Corresponding authors: Javanmardi@sutech.ac.ir; amir_h_mohammadi@yahoo.com

a Jafar Javanmardi and Amir H. Mohammadi contributed equally.
}

$T$

$f^{0}(T)$

$f^{0}(P)$

$f^{0}\left(a_{w}\right)$

$A^{\prime}, B^{\prime}, C^{\prime}$ Antoine constants for calculating $f^{0}(T)$

B Structural parameter

$P \quad$ Pressure

$\Delta V \quad$ The molar volume differences

$R \quad$ Universal gas constant

$a_{w} \quad$ Activity of water

$x_{\text {salt }}$

$k_{1}, k_{2}$

$P_{c}$

$T_{c}$

$Z_{c}$

$\omega$

$\mathrm{AAD}$

AARD

$T_{\text {Exp }}$
Mole fraction of salt in the aqueous phase

Tuning parameters

Critical pressure

Critical temperature

Compressibility factor

Acentric factor

Average Absolute Deviations

Average Absolute Relative Deviations

Experimental temperature 
$T_{\text {Cal }} \quad$ Calculated temperature

$P_{\text {Exp }} \quad$ Experimental pressure

$P_{\text {Cal }} \quad$ Calculated pressure

$\Delta T_{\text {inc }} \quad$ The average increase in the hydrate dissociation temperature in the presence of thermodynamic promoter

\section{Introduction}

Pursuant to the U.S. Energy Information Administration report, Natural Gas (NG) emits less carbon dioxide than oil and coal. Therefore, NG can be used as a clean fuel [1]. It is also a primary feed in many industrial plants and plays a vital role in energy supply with increasing the population and global demand. NG has received more attention and has been developed in recent decades more than other fossil fuels. Unlike other fossil fuels, the emanation of oxides of sulfur, carbon, and nitrogen by NG is negligible so that NG reduces environmental pollution. Storage and transportation of NG have several challenges with respect to crude oil and multiple methods are utilized for transport and storage of NG for example pipelines, Liquefied Natural Gas (LNG), Compressed Natural Gas (CNG), and clathrate/gas hydrates $[2,3]$.

Although the clathrate hydrate formation in the gas pipelines can lead to some drawbacks, the formation of clathrate hydrates can also present a variety of potential applications. One of the most important and practical applications of clathrate hydrates is the storage and transportation of NG [3-5]. Clathrate hydrates are solid crystalline mixtures that appear in the presence of water molecules connecting through hydrogen bonds and guest molecules (gas and/or some volatile liquid molecules) in desirable pressure/temperature circumstances [6]. Heretofore, three typical structures of clathrate hydrates have been well studied. However, in the presence of some quaternary ammonium salts, an unusual structure called semi-clathrate hydrate can be formed [7-11]. Semi-clathrate hydrates are analogous to clathrate hydrates in most of the structure and physical properties, but unlike clathrate hydrates, in semi-clathrate hydrates, both water and anion contribute to lattice formation while the cation occupies the large cavities [9]. The aforementioned quaternary ammonium salts are well-known as Thermodynamic Hydrate Promoters (THPs) (in a specific range of the quaternary ammonium salt concentration in the aqueous phase) which are capable of diminishing the hydrate phase equilibrium pressures. TetraButyl Ammonium $\left(\mathrm{TBA}^{+}\right)$salts with distinct anions like $\left(\mathrm{Br}^{-}, \mathrm{Cl}^{-}, \mathrm{F}^{-}\right.$, and $\left.\mathrm{P}^{-}\right)$can be considered as the most distinguished and leading THPs [9, 12-15].

Based on the aforementioned explanations, tetrabutylammonium halides can form semi-clathrate hydrates. From a molecular point of view, water molecules and anions take part in the formation of the crystalline hydrate framework in which the tiny guest molecules such as, $\mathrm{CH}_{4}, \mathrm{CO}_{2}$, etc., settle in the small cavities while salt cation fills the large cavities $[10,13]$. Therefore, in semi-clathrate hydrates of $\mathrm{TBAB}, \mathrm{TBA}^{+}$, locates at the center of large cavities while the halide anion, $\mathrm{Br}^{-}$plays as an alternative of a pair of water molecules in a crystal framework by forming hydrogen bonds with adjacent water molecules [13-19]. Diverse structures exist for TBAB semi-clathrate hydrate owning several hydration numbers. Nevertheless, two basic types of structure for TBAB hydrate have been proposed with hydration numbers of 26 and 38, referred to as types $\mathrm{A}$ and $\mathrm{B}$ of semi-clathrate hydrates, respectively $[9,12$, 19-21]. Types A and B of semi-clathrate hydrates are functions of the salt concentration in the aqueous phase and result in different semi-clathrate hydrates phase equilibrium conditions [10, 22].

In recent years, plentiful data for the methane + TBAB + water system have been reported. Li et al. [23] measured the hydrate phase equilibrium data (hydrate dissociation conditions data or hydrate phase stability conditions data) for $\mathrm{CH}_{4}+\mathrm{TBAB}+\mathrm{H}_{2} \mathrm{O}$ system. They observed that the hydrate stability conditions are shifted to low pressures and high temperatures in the presence of TBAB. Arjmandi et al. [24] measured hydrate phase equilibrium data for some gases $+\mathrm{TBAB}+$ water system. Sun and Sun [17] investigated the methane semi-clathrate hydrate phase stability conditions for various mass fractions of TBAB. Their data demonstrates that TBAB diminishes the phase equilibrium pressure of methane hydrate. Mohammadi and Richon [25] experimentally determined phase equilibrium data of semi-clathrate hydrates of $\mathrm{CH}_{4} / \mathrm{H}_{2} \mathrm{~S}+$ TBAB + water. Gholinezhad et al. [26] analyzed the impact of 40.7 wt. $\%$ of TBAB on methane semi-clathrate hydrate phase stability conditions. They concluded that this concentration leads to the most stable semi-clathrate hydrate in the three-phase equilibrium conditions. Lee et al. [27] performed the measurements of the hydrate phase equilibrium data of $\mathrm{CH}_{4} / \mathrm{CO}_{2}+\mathrm{TBAB}+\mathrm{H}_{2} \mathrm{O}$ systems. They indicated that the 3.7 mole $\%$ of TBAB leads to the highest stability of semiclathrate hydrate. Mohammadi et al. [28] measured the semi-clathrate hydrate phase stability conditions of some gases in the presence of various mass fractions of TBAB. Liao et al. [29] explicated the impact of TBAB on the semi-clathrate hydrates of some gases and employed the Chen-Guo model [30, 31] to predict their experimental data. Roosta et al. [32] perused the efficiencies of some promoters on the methane hydrate formation kinetics. Sangwai and Oellrich [33] studied the impacts of TBAB and TBAB + $\mathrm{NaCl}$ on methane hydrate formation. Mech et al. [34] assayed the effects of some inhibitors on the methane hydrate formation in the existence of TBAB and Tetra HydroFuran (THF). Najibi et al. [35] investigated methane semi-clathrate hydrate phase stability conditions in the presence of TBAB. Also, they utilized the van der WaalsPlatteeuw (vdW-P) model [36] to correlate the experimental data. Verrett et al. [37] conducted the phase equilibrium data of $\mathrm{CH}_{4}$ and $\mathrm{CO}_{2}$ hydrates in the presence of TBAB. Also, they presented a thermodynamic model to predict their data. Long et al. [38] measured the hydrate phase stability conditions of $\mathrm{CH}_{4} / \mathrm{CO}_{2}+\mathrm{TBAB}+$ water systems in the $P$ and $T$ ranges of $0.54-14.57 \mathrm{MPa}$ and $273.6-294.2 \mathrm{~K}$, respectively. Alongside the experimental studies, various thermodynamic modeling studies on gas + ammoniumbased salts + water systems have been presented [39-47]. 
Table 1. Information and suppliers' names of materials used in this work.

\begin{tabular}{lccc}
\hline Material & Chemical formula & Supplier & Purity \\
\hline Methane & $\mathrm{CH}_{4}$ & Air product & 0.9995 (mole fraction) \\
TetraButylAmmonium Bromide (TBAB) & $\left(\mathrm{CH}_{3} \mathrm{CH}_{2} \mathrm{CH}_{2} \mathrm{CH}_{2}\right)_{4} \mathrm{~N}(\mathrm{Br})$ & Merck & $\geq 0.9900$ (mass fraction) \\
TetraButylAmmonium Acetate (TBAA) & $\left(\mathrm{CH}_{3} \mathrm{CH}_{2} \mathrm{CH}_{2} \mathrm{CH}_{2}\right)_{4} \mathrm{~N}\left(\mathrm{OCOCH}_{3}\right)$ & Sigma-Aldrich & 0.9700 (mass fraction) \\
\hline
\end{tabular}

The aim of this work was to study the phase equilibrium conditions of semi-clathrate hydrates for methane $+\mathrm{TBAB}$ and TetraButylAmmonium Acetate (TBAA) + water systems. TBAB that is the most extensively used ammonium salt is considered as THP. Methane semi-clathrate hydrate equilibrium conditions in the presence of three distinct TBAB mass fractions of $0.0350,0.0490$, and 0.1500 were experimentally measured. Furthermore, the impact of another ammonium salt (TBAA) on methane semiclathrate hydrate phase equilibrium conditions at the mass fraction of 0.0990 was experimentally investigated. Finally, the modified Chen-Guo model was employed to correlate the phase equilibrium data of methane semi-clathrate hydrates in the presence of TBAB and TBAA.

\section{Experimental section}

The suppliers' names and information of the materials used in this study are reported in Table 1.

The double-distilled water was made in the laboratory of the Shiraz University of Technology using the water purification system ( $M-U V-3$, Zolalan Company, Iran). All the aqueous solutions were prepared using the gravimetric method via a digital A\&D balance (HR-200) with an uncertainty of $\pm 0.0001 \mathrm{~g}$.

In this work, all the experimental measurements were conducted in the Stainless Steel (SS-316) cell. This vessel has an effective volume of 75 cubic centimeters and can be pressurized up to $15 \mathrm{MPa}$. A magnetic stirrer is tasked with making effective agitation of the mixture at a rate of $1000 \mathrm{rpm}$. The temperature of the cell is controlled by immersing it within a programmable ethanol cooling bath and circulator (Julabo FP-50, TCS-1). This smart temperature controller is able to decrease the cell temperature at a slow rate or step by step. A PT-100 thermometer with a maximum uncertainty of $\pm 0.1 \mathrm{~K}$ measures the cell temperature. The cell pressure is measured using a $\mathrm{P}-2$ transmitter (ABB) with an uncertainty of $\pm 0.01 \mathrm{MPa}$. A Data Acquisition System (DAS) is applied for gathering data of the system and converting analog waveforms into digital values for processing. Figure 1 presents a schematic diagram of the instruments.

In the first instance, the cell was rinsed with doubledistilled water and dried entirely. Twenty cubic centimeters of the aqueous solutions of TBAB or TBAA were prepared and introduced into the cell, it was then evacuated. Thereupon, the cell was pressurized with the methane gas to reach the required pressure. The isochoric pressure search method [48-52] was employed to measure the semi-clathrate hydrate phase equilibrium conditions. Initially, the pressure was adjusted to the pressure higher than the equilibrium pressure required for the semi-clathrate hydrate dissociation. The system temperature was then decreased by a slow rate until the point at which the semi-clathrate hydrate was formed totally. Then, the system temperature was increased at an extremely slow rate $\left(0.1 \mathrm{~K} \cdot \mathrm{h}^{-1}\right)$ until the last particle of hydrate dissociated. The point at which the last particle of the crystal vanished and the slope of the $P-T$ curve changed was considered as the semi-clathrate hydrate dissociation point [48-52].

\section{Thermodynamic model}

In this study, the extended Chen-Guo model proposed by Joshi et al. [40] was used to compute the semi-clathrate hydrate phase equilibrium conditions of methane $+\mathrm{TBAB}+$ water and methane + TBAA + water systems. In the original Chen-Guo model [30,31], a simple reaction represents the hydrate formation mechanism [30, 31, 40]:

$$
\mathrm{H}_{2} \mathrm{O}+\lambda_{2} \mathrm{G} \rightarrow \mathrm{G}_{\lambda 2} \cdot \mathrm{H}_{2} \mathrm{O} .
$$

In equation (1), $G$ is the guest (here gas) molecule, and $\lambda_{2}$ represents the ratio of the number of guest molecules to the number of water molecules. The basis of the phase equilibrium conditions is the equality of the fugacity [30, 31, 40]:

$$
f=f^{0}(1-\theta)^{\alpha} .
$$

In equation (2), $f$ defines the gas phase fugacity and $f^{0}$ represents the fugacity of the gas molecules in equilibrium with an unoccupied basic hydrate. $\alpha$ is a dimensionless factor that is given as follows [30, 31, 40]:

$$
\alpha=\frac{\lambda_{1}}{\lambda_{2}} .
$$

In equation (3), $\lambda_{1}$ describes the ratio of the number of linked cavities to the number of water molecules. Semiclathrate hydrates may form two different structures, types $\mathrm{A}$ and $\mathrm{B}$, as mentioned earlier. Based on quaternary ammonium salt concentration, if the salt content is below 0.1800 mass fraction, type $\mathrm{B}$ has a higher melting point and is stable, otherwise type A can form [41]. Table 2 indicates the structural specifications of types A and B of semiclathrate hydrates [45]:

$\theta$ stands for the fractional occupancy of cavities [30, $31,40]$ :

$$
\theta=\frac{C f}{1+C f} .
$$




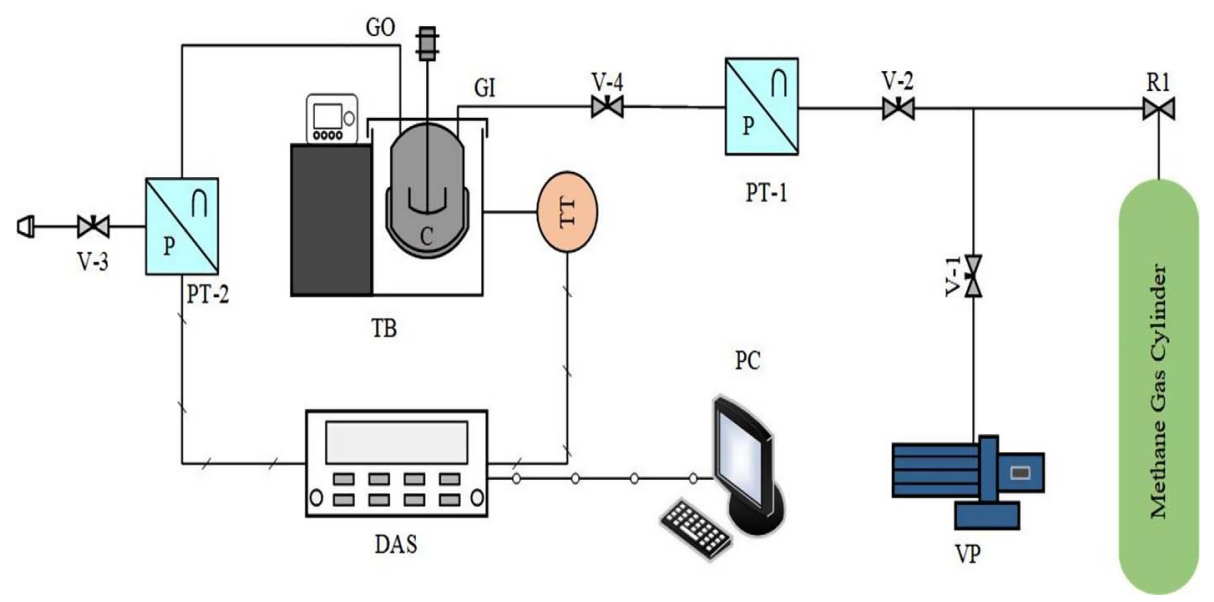

Fig. 1. A schematic diagram of the setup. R, Regulator; V, Valve; P, Pressure; PT, Pressure Transducer; PC, Personal Computer; TT, Temperature Transmitter; TB, Thermostatic Bath; C, Cell; GI, Gas In; GO, Gas Out; DAS, Data Acquisition System; VP, Vacuum Pump.

Table 2. The structural specifications of types A and B for a unit cell [45].

\begin{tabular}{lcc}
\hline Properties & Type A & Type B \\
\hline Hydrate number & 26 & 38 \\
Number of the linked cavities & 1.65 & 1.75 \\
Number of the gas molecules & 3 & 3 \\
$\lambda_{1}$ & $1.65 / 26$ & $1.75 / 38$ \\
$\lambda_{2}$ & $3 / 26$ & $3 / 38$ \\
$\alpha$ & $1.65 / 3$ & $1.75 / 3$ \\
\hline
\end{tabular}

Table 3. The critical properties, acentric factor, and the parameters required in equations (5) and (7).

The critical properties and the acentric factor of methane [54].

\begin{tabular}{lcc}
\hline$P_{c} / \mathrm{MPa}$ & $T_{c} / \mathrm{K}$ & $\omega$ \\
4.599 & 190.564 & 0.0115
\end{tabular}

Values of the Langmuir constant of methane used in equation (5) [45].

\begin{tabular}{lcc}
\hline$X \times 10^{5} / \mathrm{MPa}^{-1}$ & $Y / \mathrm{K}$ & $Z / \mathrm{K}$ \\
2.3048 & 2752.29 & 23.01
\end{tabular}

Values of the Antoine constants of methane used in equation (7) [45].

\begin{tabular}{lcc}
\hline$A^{\prime} \times 10^{-22} / \mathrm{MPa}$ & $B^{\prime} / \mathrm{K}$ & $C^{\prime} / \mathrm{K}$ \\
5.2602 & -12955 & 4.08 \\
\hline
\end{tabular}

$P_{c}$ : the critical pressure; $T_{c}$ : the critical temperature; $\omega$ : the acentric factor.

The filling of the hydrate cavities by the guest molecules is simulated as adsorption of the guest molecules on the solid surfaces that is described by the Langmuir ideal adsorption theory [36]. In equation (4), $C$ is the Langmuir constant that can be computed for each guest molecule

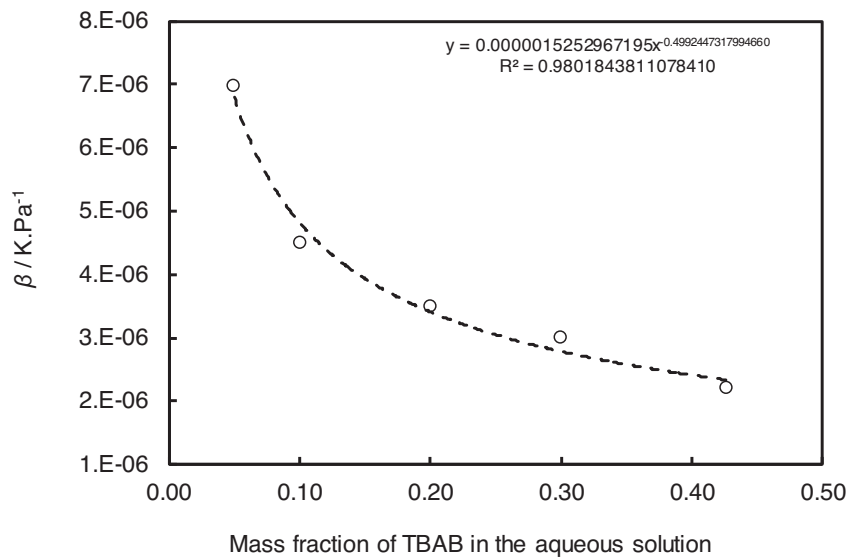

Fig. 2. Reported values of the structural parameter $(\beta)$ against TBAB mass fraction in the aqueous solution [44].

through an appropriate potential function or semi-empirical correlations. In this work, $C$ was calculated by the following semi-empirical Antoine-like correlation [31]:

$$
C=X \exp \left(\frac{Y}{T-Z}\right) \text {. }
$$

In equation (5), $X, Y$, and $Z$ are the Antoine constants, and $T$ stands for the system absolute temperature.

Since the vapor pressures of quaternary ammonium salts as a kind of Ionic Liquids (ILs) are very low compared to methane, therefore, it is assumed that only methane exists in the gas phase. The Peng-Robinson (PR) EoS [53] is put into action to calculate the gas phase fugacity.

In equation $(2), f^{0}$ is dependent on pressure, temperature, and water activity [30, 31, 40]:

$$
f^{0}=f^{0}(T) f^{0}(P) f^{0}\left(a_{w}\right),
$$

where:

$$
f^{0}(T)=A^{\prime} \exp \left(\frac{B^{\prime}}{T-C^{\prime}}\right)
$$


Table 4. The structural parameter $(\beta)$ for TBAB and TBAA at various mass fractions.

\begin{tabular}{lccc}
\hline Quaternary ammonium salt & Mass fraction & $\beta / \mathrm{K} \cdot \mathrm{MPa}^{-1}$ & Calculation method \\
\hline TBAB & 0.0350 & 8.1324 & Extrapolated using Figure 2 \\
& 0.0490 & 6.8749 & Extrapolated using Figure 2 \\
& 0.1500 & 3.9326 & Interpolated using Figure 2 \\
TBAA & 0.0990 & 4.5000 & Optimized in this work \\
\hline
\end{tabular}

$$
\begin{gathered}
f^{0}(P)=\exp \left(\frac{\beta P}{T}\right), \\
f^{0}\left(a_{w}\right)=a_{w}^{-1 / \lambda_{2}} .
\end{gathered}
$$

In equation (7), $A^{\prime}, B^{\prime}$, and $C^{\prime}$ are the constants that are specific for each guest molecule. The parameters required for the calculation of $C$ using (Eq. (5)) and $f^{0}(T)$ using (Eq. (7)), as well as the critical properties and acentric factor for methane, are presented in Table $3[45,54]$.

In equation (8), $\beta$ is a structural parameter that can be defined as [30, 31, 40]:

$$
\beta=\frac{\Delta V}{\lambda_{2} R}
$$

In equation (10), $\Delta V$ is the molar volume difference and $R$ represents the universal gas constant. Since the anion of the quaternary ammonium salt contributes to the semiclathrate structure, $\beta$ has a different value for each concentration of quaternary ammonium salt. For TBAB, the values of $\beta$ available in the literature were plotted against TBAB concentration and an appropriate curve was constructed that has the best fit to the data points. Figure 2 demonstrates the values of $\beta$ against the TBAB concentration in the aqueous solution.

Consequently, at each TBAB mass fraction, $\beta$ can be calculated by interpolation or extrapolation of the points through the curve. For TBAA no data is available in the literature, therefore, for TBAA, $\beta$ was optimized using the experimental dissociation conditions data of methane + TBAA semi-clathrate hydrate measured in this work. Table 4 indicates the values of $\beta$ for the concentrations of TBAB and TBAA studied in this work.

In equation (9), $a_{w}$ denotes the water activity that can be calculated as follows [30, 31, 40]:

$$
a_{w}=\frac{1}{1-x_{\text {salt }}} \exp \left(\frac{k_{1}}{T}-k_{2}\right) .
$$

In equation (11), $a_{w}$ represents the water activity in the aqueous solution, $x_{\text {salt }}$ stands for the mole fraction of quaternary ammonium salt in the aqueous solution, $T$ is the absolute temperature. $k_{1}$ and $k_{2}$ are the tuning parameters that are dependent on the concentration of quaternary ammonium salt that can be optimized using the following objective function:

$$
\text { O.F. }=\sum \frac{100}{\mathrm{ND}} \frac{\left|T_{\mathrm{Exp}}-T_{\text {Cal }}\right|}{T_{\mathrm{Exp}}}
$$

Finally, by incorporating equations (2) and (6)-(9), the following governing equation is gained [30, 31, 40]:

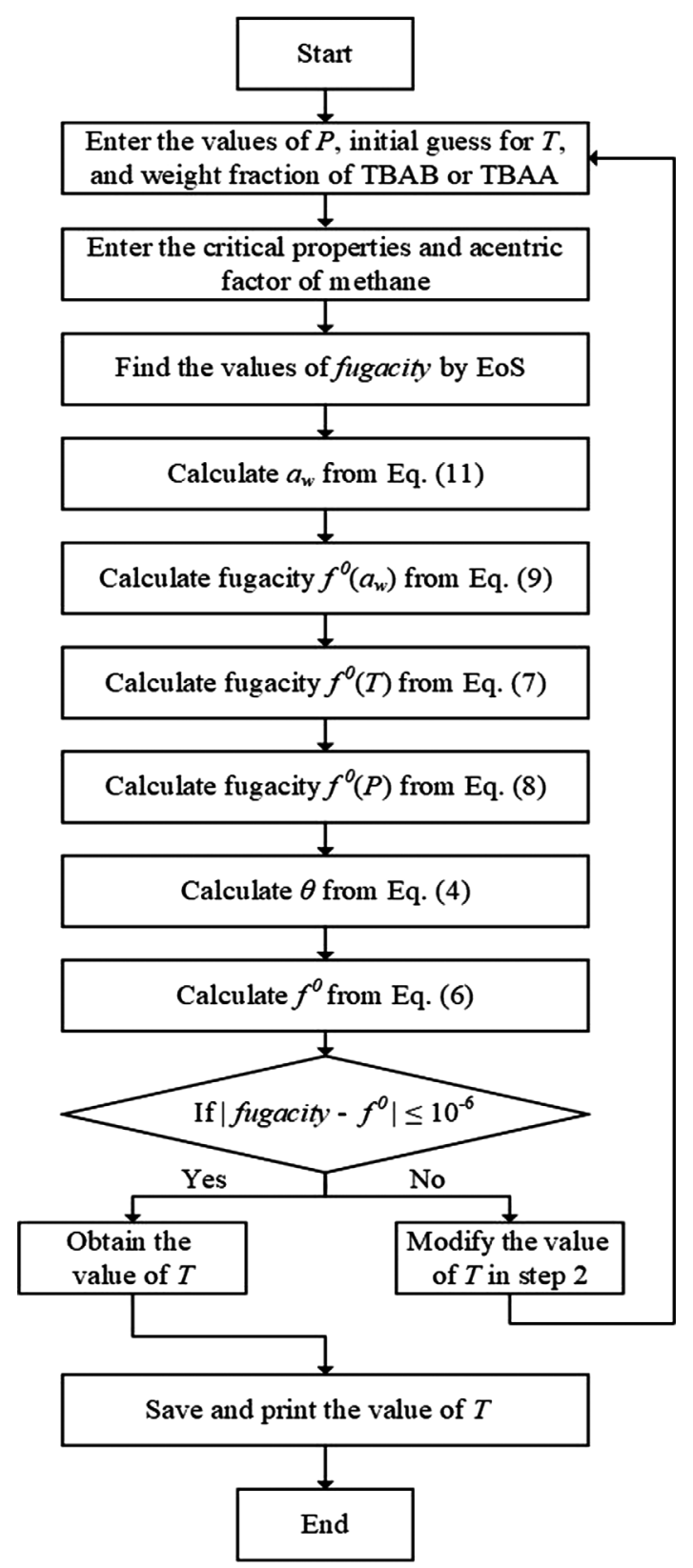

Fig. 3. Flowchart of the model used in this work.

$$
\begin{aligned}
f= & {\left[A^{\prime} \exp \left(\frac{B^{\prime}}{T-C^{\prime}}\right) \exp \left(\frac{\beta P}{T}\right)\left(\frac{1}{1-x_{\text {salt }}} \exp \left(\frac{k_{1}}{T}-k_{2}\right)\right)^{-\frac{1}{\lambda_{2}}}\right] } \\
& \times(1-\theta)^{\alpha} .
\end{aligned}
$$


Table 5. Experimental data of methane semi-clathrate hydrate phase stability conditions in the presence of TBAB aqueous solutions.

\begin{tabular}{|c|c|c|c|c|c|}
\hline$P / \mathrm{MPa}^{a}$ & $T / \mathrm{K}^{\mathrm{b}}$ & $P / \mathrm{MPa}$ & $T / \mathrm{K}$ & $\underline{P / \mathrm{MPa}}$ & $T / \mathrm{K}$ \\
\hline \multicolumn{2}{|c|}{$w_{\text {TBAB }}{ }^{c}=0.0350^{d}$} & \multicolumn{2}{|c|}{$w_{\mathrm{TBAB}}=0.0490$} & \multicolumn{2}{|c|}{$w_{\mathrm{TBAB}}=0.1500$} \\
\hline 1.91 & 281.9 & 1.59 & 282.3 & 1.31 & 286.5 \\
\hline 2.11 & 282.1 & 1.84 & 283.0 & 1.57 & 287.0 \\
\hline 2.37 & 282.6 & 1.99 & 283.3 & 1.73 & 287.3 \\
\hline 2.81 & 283.4 & 2.41 & 284.0 & 2.11 & 287.9 \\
\hline 3.25 & 283.9 & 2.86 & 284.7 & 2.84 & 289.0 \\
\hline 3.83 & 284.7 & 3.88 & 285.7 & 3.35 & 289.5 \\
\hline 4.36 & 285.2 & 4.34 & 286.2 & 4.07 & 290.1 \\
\hline 4.56 & 285.4 & 5.10 & 287.0 & 4.77 & 290.7 \\
\hline 4.81 & 285.6 & 5.90 & 287.4 & 5.36 & 291.2 \\
\hline 5.14 & 285.9 & 6.77 & 288.0 & 6.11 & 291.7 \\
\hline 5.54 & 286.1 & 6.84 & 288.1 & 6.99 & 292.2 \\
\hline 5.96 & 286.5 & - & - & 7.51 & 292.4 \\
\hline 6.80 & 287.0 & - & - & 7.61 & 292.4 \\
\hline
\end{tabular}

${ }^{a}$ The expanded uncertainties $\left(U_{c}\right)$ in the reported pressures are about $\pm 0.01 \mathrm{MPa}$.

b The expanded uncertainties $\left(U_{c}\right)$ in the reported temperatures are about $\pm 0.1 \mathrm{~K}$.

${ }^{\mathrm{c}}$ Mass fraction of TBAB in the aqueous solution.

d The expanded uncertainties $\left(U_{c}\right)$ in the reported mass fractions are about \pm 0.0001 .

Table 6. Experimental data of methane semi-clathrate hydrate phase stability conditions in the presence of TBAA aqueous solution.

\begin{tabular}{lcc}
\hline Mass fraction of TBAA & $P / \mathrm{MPa}^{\mathrm{a}}$ & $T / \mathrm{K}^{\mathrm{b}}$ \\
\hline $0.0990^{\mathrm{c}}$ & 2.66 & 283.9 \\
2.87 & 284.1 \\
3.05 & 284.3 \\
3.58 & 284.8 \\
4.25 & 285.4 \\
4.50 & 285.6 \\
4.72 & 285.7 \\
5.20 & 286.0 \\
5.64 & 286.4 \\
6.13 & 286.8 \\
6.33 & 286.9 \\
6.70 & 287.1 \\
& 7.35 & 287.4 \\
7.88 & 287.8 \\
8.88 & 288.2 \\
9.23 & 288.3 \\
\hline
\end{tabular}

a The expanded uncertainties $\left(U_{c}\right)$ in the reported pressures are about $\pm 0.01 \mathrm{MPa}$.

b The expanded uncertainties $\left(U_{c}\right)$ in the reported temperatures are about $\pm 0.1 \mathrm{~K}$.

${ }^{\mathrm{c}}$ The expanded uncertainties $\left(U_{c}\right)$ in the reported mass fractions are about \pm 0.0001 .

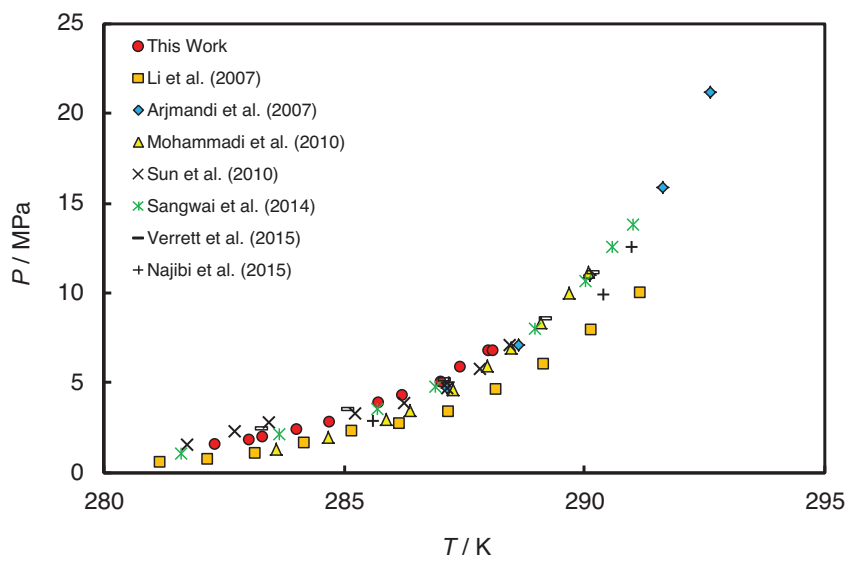

Fig. 4. Methane semi-clathrate hydrate phase stability conditions data for 0.0500 mass fraction of TBAB in the aqueous solution.

By solving equation (13), the phase equilibrium condition of methane semi-clathrate hydrate is obtained. The flowchart of the model is presented in Figure 3.

\section{Results and discussion}

In this study, the phase stability conditions of methane semi-clathrate with TBAB and TBAA were first experimentally measured. There exist several experimental data 
Table 7. The optimized constants for calculating the activity of water (Eq. (11)).

\begin{tabular}{|c|c|c|c|c|c|}
\hline Gas & Quaternary ammonium salt & Mass fraction & $T$ range & $k_{1} / \mathrm{K}$ & $k_{2}$ \\
\hline \multirow[t]{4}{*}{ Methane } & TBAB & 0.0350 & $281.9 \leq T \leq 287.0$ & 652.526 & 1.962 \\
\hline & & 0.0490 & $282.3 \leq T \leq 288.1$ & 843.704 & 2.607 \\
\hline & & 0.1500 & $286.5 \leq T \leq 292.4$ & 1216.127 & 3.799 \\
\hline & TBAA & 0.0990 & $283.9 \leq T \leq 288.3$ & 967.775 & 3.067 \\
\hline
\end{tabular}

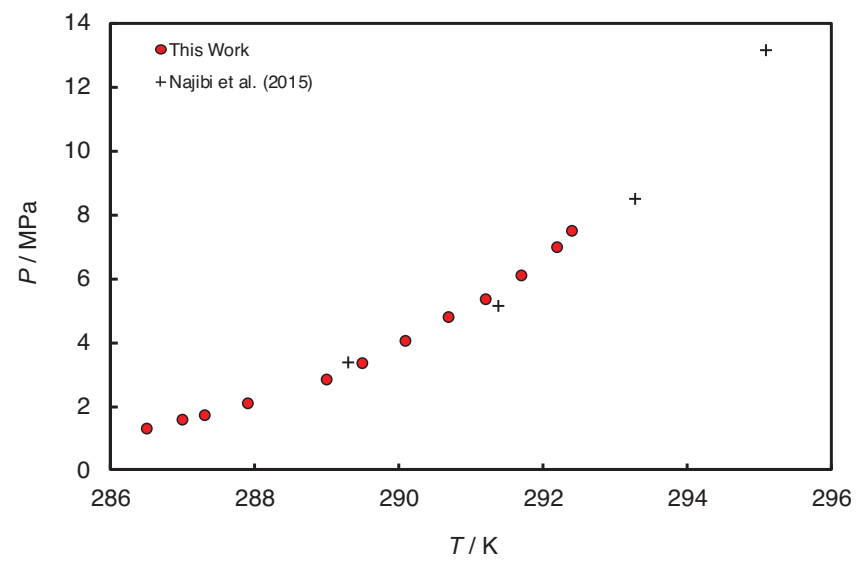

Fig. 5. Methane semi-clathrate hydrate phase stability conditions data for 0.1500 mass fraction of TBAB in the aqueous solution.

on phase equilibrium data of methane semi-clathrate + TBAB in the literature while no experimental data exists for methane semi-clathrate with TBAA, to the best of our knowledge. A total of 53 equilibrium data for methane semi-clathrate + ammonium salts containing 37 data for methane + TBAB and 16 data for methane + TBAA were measured. Three concentrations for TBAB containing $0.0350,0.0490$, and 0.1500 mass fractions and a mass fraction of 0.0990 for TBAA were used. Tables 5 and 6 display the methane semi-clathrate phase stability conditions in the presence of TBAB and TBAA aqueous solutions, respectively.

It is clear that methane semi-clathrate hydrates in the presence of TBAB and TBAA are formed at milder conditions compared to pure methane hydrate (higher temperatures and lower pressures). The reason is due to fact that the cation of TBAB/TBAA (TetraButylAmmonium Acetate) occupies the large cavities leading to better stabilization of the semi-clathrate structure. Moreover, TBAB and TBAA have an impact on water activity due to the interactions between the water and quaternary ammonium salt in the aqueous solution.

To check the precision of the experimental procedure and equipment, the experimental data of methane semiclathrate hydrate phase stability conditions measured in this work were compared with the available experimental data in the literature. Figures 4 and 5 give a comparison between the experimental data reported in the literature and those for TBAB mass fractions of 0.0500 and 0.1500 , respectively.

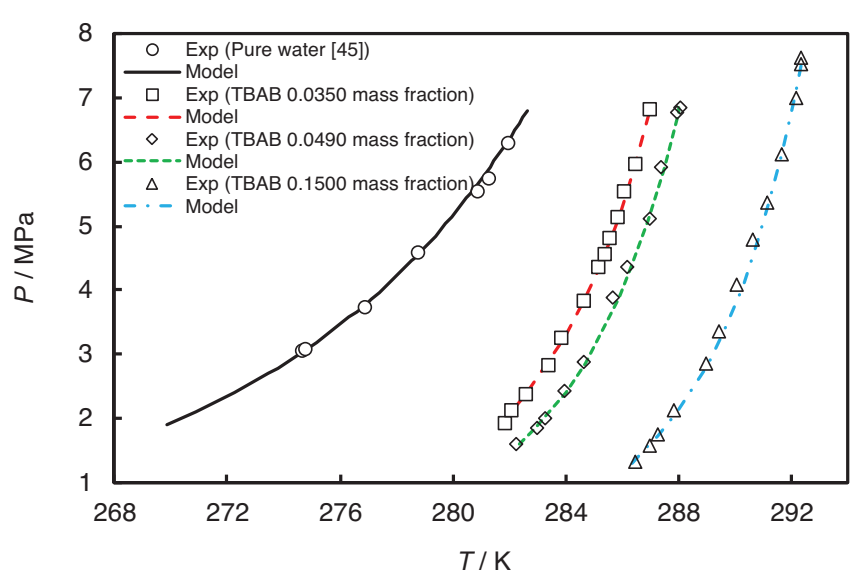

Fig. 6. Comparison between the methane semi-clathrate hydrate phase stability conditions in the presence of pure water and TBAB aqueous solutions.

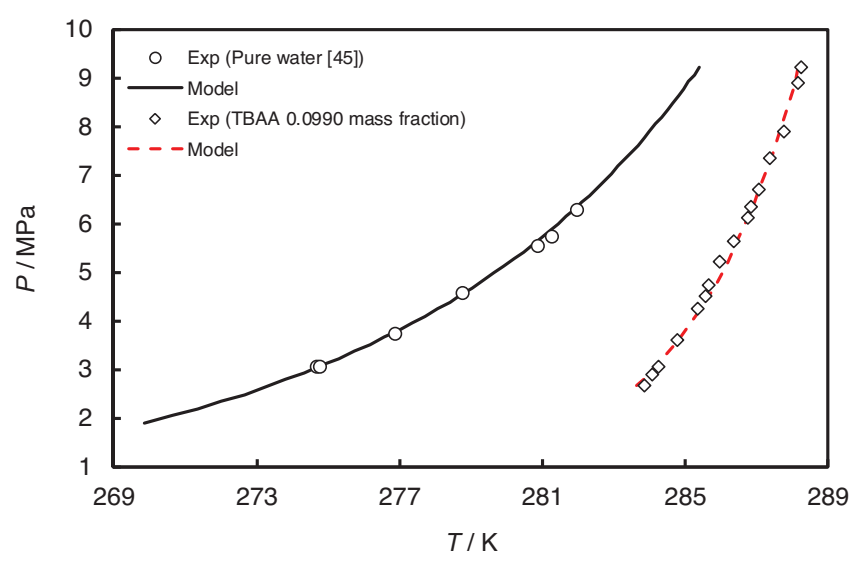

Fig. 7. Comparison between the methane semi-clathrate hydrate phase stability conditions in the presence of pure water and TBAA aqueous solution.

It is interpreted from Figures 4 and 5 that the experimental data measured in this work for the methane + TBAB + water system are in agreement with the experimental data reported in the literature. Therefore, we can trust the accuracy and precision of the procedure and equipment for the methane + water + TBAA system.

To calculate water activity in the presence of quaternary ammonium salts, a simple relation can be used (Eq. (11)). In equation (11), $k_{1}$ and $k_{2}$ are optimized using the experimental data for methane semi-clathrate hydrate phase stability 
Table 8. The errors of the model in determining methane semi-clathrate phase stability conditions in the presence of TBAB and TBAA aqueous solutions.

\begin{tabular}{lccccccc}
\hline Aqueous phase & $\mathrm{NP}$ & $T$ range $/ \mathrm{K}$ & $P$ range $/ \mathrm{MPa}$ & $(\mathrm{AAD})_{T} / \mathrm{K}$ & $(\mathrm{AARD})_{T}$ & $(\mathrm{AAD})_{P} / \mathrm{MPa}$ & $(\mathrm{AARD} \%)_{P}$ \\
\hline$w_{\text {TBAB }}=0.0350$ & 13 & $281.9-287.0$ & $1.91-6.80$ & 0.0 & 0.015 & 0.03 & 1.003 \\
$w_{\text {TBAB }}=0.0490$ & 11 & $282.3-288.1$ & $1.59-6.84$ & 0.1 & 0.023 & 0.07 & 1.704 \\
$w_{\text {TBAB }}=0.1500$ & 13 & $286.5-292.4$ & $1.31-7.61$ & 0.1 & 0.024 & 0.08 & 2.030 \\
$w_{\text {TBAA }}=0.0990$ & 16 & $283.9-288.3$ & $2.66-9.23$ & 0.1 & 0.030 & 0.13 & 2.381 \\
Total & 53 & $281.9-292.4$ & $1.31-9.23$ & 0.1 & 0.023 & 0.08 & 1.780 \\
\hline
\end{tabular}

NP: Number of points.

conditions measured in this work. Table 7 indicates $k_{1}$ and $k_{2}$ values for TBAB and TBAA at each quaternary ammonium salt concentration in the aqueous phase.

Figures 6 and 7 compare the experimental data and modeling outputs for methane semi-clathrate hydrate phase stability conditions in the presence of pure water, TBAB, and TBAA aqueous solutions.

It can be qualitatively concluded from Figures 6 and 7 that the applied model can accurately calculate the methane semi-clathrate hydrate phase stability conditions in the presence of diverse TBAB and TBAA aqueous solutions. To elucidate the aforementioned explanations quantitively, the errors of the model in calculating the methane semiclathrate hydrate phase equilibrium conditions are presented that were calculated using the following equations:

$$
\begin{gathered}
(\mathrm{AAD})_{T}(\mathrm{~K})=\sum \frac{1}{\mathrm{ND}}\left|T_{\text {Exp }}-T_{\text {Cal }}\right| \\
(\mathrm{AARD} \%)_{T}=\sum \frac{100}{\mathrm{ND}} \frac{\left|T_{\text {Exp }}-T_{\text {Cal }}\right|}{T_{\text {Exp }}}, \\
(\mathrm{AAD})_{P}(\mathrm{MPa})=\sum \frac{1}{\mathrm{ND}}\left|P_{\text {Exp }}-P_{\mathrm{Cal}}\right|, \\
(\mathrm{AARD} \%)_{P}=\sum \frac{100}{\mathrm{ND}} \frac{\left|P_{\operatorname{Exp}}-P_{\text {Cal }}\right|}{P_{\text {Exp }}},
\end{gathered}
$$

where ND represents number of data.

Table 8 indicates the errors of the modified Chen-Guo model [30,31] employed in this work to calculate methane semi-clathrate phase stability conditions in the presence of TBAB and TBAA.

It can be concluded from Table 8 that the modified Chen-Guo model $[30,31]$ can precisely correlate the methane semi-clathrate hydrate phase stability conditions. The $(\mathrm{AAD})_{T}$ and $(\mathrm{AAD})_{P}$ of the model are $0.1 \mathrm{~K}$ and $0.08 \mathrm{MPa}$, respectively.

The calculated water activity values for various $T B A B$ and TBAA aqueous solutions were plotted against the temperature to indicate the impacts of temperature and quaternary ammonium salt concentration in the aqueous phase on water activity.

It can be seen from Figure 8 that 0.1500 mass fraction of $\mathrm{TBAB}$ in the aqueous solution increases water activity much more than the other aqueous solutions. This confirms

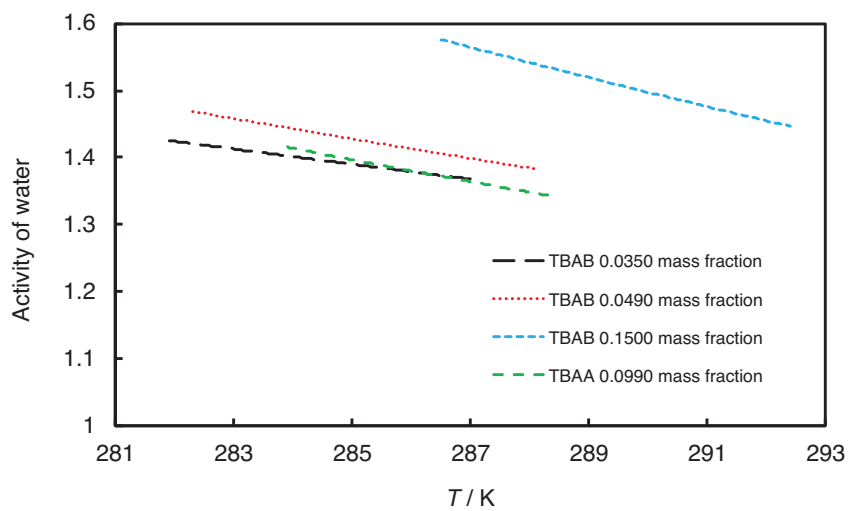

Fig. 8. The calculated values of water activity against temperature for various quaternary ammonium salts concentrations in the aqueous phase.

the fact that the aqueous solution with a 0.1500 mass fraction of TBAB is capable of promoting the methane hydrate phase stability conditions much more than the other aqueous solutions. The results indicate that both TBAB and TBAA shift the methane hydrate stability conditions to higher temperature/lower pressure conditions and act as THP. Table 9 presents the average temperature shift by the applied quaternary ammonium salts at various concentrations.

Two conclusions are gained from Table 9: the temperature increments for $0.0350,0.0490$, and 0.1500 mass fractions of TBAB are 7.7, 9.4, and $13.5 \mathrm{~K}$, respectively. This value for 0.0990 mass fraction of TBAA is $6.2 \mathrm{~K}$. Therefore, it is concluded that TBAB is a stronger thermodynamic promoter of methane hydrate compared to TBAA. Since TBAB and TBAA have different anions, they have different impacts on methane hydrate stability conditions. It has been proved that anion has a great impact on semi-clathrate hydrate phase equilibrium and by increasing the $\mathrm{TBAB}$ concentration, the temperature increment also increases [55]. According to the references [55, 56], TetraButylAmmonium Fluoride (TBAF) is the best thermodynamic promoter than other ammonium salts and it can make a stronger hydrogen bond with water molecules. However, it has a strong toxic nature because of the presence of fluoride ion in TBAF. Also, as the size of the anion increases, this bond becomes weaker. 
Table 9. The comparison between the temperature increments of TBAB and TBAA at various mass fractions.

\begin{tabular}{lcccc}
\hline Aqueous phase & NP & $T$ range $/ \mathrm{K}$ & $P$ range $/ \mathrm{MPa}$ & $\Delta T_{\text {inc }} / \mathrm{K}$ \\
\hline$w_{\text {TBAB }}=0.0350$ & 13 & $281.9-287.0$ & $1.91-6.80$ & 7.7 \\
$w_{\text {TBAB }}=0.0490$ & 11 & $282.3-288.1$ & $1.59-6.84$ & 9.4 \\
$w_{\text {TBAB }}=0.1500$ & 13 & $286.5-292.4$ & $1.31-7.61$ & 13.5 \\
$w_{\text {TBAA }}=0.0990$ & 16 & $283.9-288.3$ & $2.66-9.23$ & 6.2 \\
\hline
\end{tabular}

$\Delta T_{\text {inc: }}$ : the average increase in the hydrate dissociation temperature in the presence of thermodynamic promoter. NP: number of points.

\section{Conclusion}

In this work, 53 phase equilibrium data for semi-clathrate hydrates of methane + TBAB/TBAA aqueous solutions were experimentally measured. Three aqueous solutions of TBAB containing $0.0350,0.0490,0.1500$ mass fractions, and one aqueous solution of TBAA containing 0.0990 mass fraction were used for this purpose. All the experimental measurements were performed using the isochoric pressure search method [48-52]. Consistency between the results for 0.0490 and 0.1500 mass fractions of TBAB reported in this work and those reported by the other groups are observed. Furthermore, the modified Chen-Guo model $[30,31]$ was used to correlate the aforementioned semiclathrate hydrates equilibrium conditions. Two parameters for $\operatorname{TBAB}\left(k_{1}\right.$ and $\left.k_{2}\right)$ and three parameters for TBAA $\left(\mathrm{k}_{1}, k_{2}\right.$, and $\left.\beta\right)$ were optimized using the experimental phase equilibrium data for the aforesaid semi-clathrate hydrates. The $(\mathrm{AAD})_{T}$ and $(\mathrm{AAD})_{P}$ of the model for all the 53 data points are $0.1 \mathrm{~K}$ and $0.08 \mathrm{MPa}$, respectively. Finally, by comparing the temperature shifts for each quaternary ammonium salt, it is concluded that TBAB is a stronger THP compared to TBAA.

Acknowledgments. Support of this work by the Shiraz University of Technology is highly acknowledged.

\section{Declaration of interests}

The authors declare that they have no known competing financial interests or personal relationships that could have appeared to influence the work reported in this paper.

\section{References}

1 US Energy Information Administration (2019) U.S. EnergyRelated Carbon Dioxide Emissions.

2 Economides M.J., Wood D.A. (2009) The state of natural gas, J. Nat. Gas Sci. Eng. 1, 1-2, 1-13. https://doi.org/ 10.1016/j.jngse.2009.03.005.

3 Mokhatab S., Poe W.A. (2012) Handbook of natural gas transmission and processing, Gulf Professional Publishing, United State of America.

4 Gudmundsson J., Borrehaug A. (1996) Frozen hydrate for transport of natural gas, in: NGH 96: 2nd International Conference on Natural Gas Hydrates, Toulouse, June 2-6, 1996, pp. 415-422.
5 Dawe R.A. (2003) Hydrate technology for transporting natural gas. http://hdl.handle.net/10576/7797.

6 Mehrabi K., Javanmardi J., Rasoolzadeh A., Mohammadi A. H. (2020) Thermodynamic modeling of clathrate hydrate stability conditions in the presence of amino acid aqueous solution, J. Mol. Liq. 313, 113488. https://doi.org/10.1016/ j.molliq.2020.113488.

7 Fowler D.L., Loebenstein W.V., Pall D.B., Kraus C.A. (1940) Some unusual hydrates of quaternary ammonium salts, J. Am. Chem. Soc. 62, 5, 1140-1142. https://doi.org/ 10.1021/ja01862a039.

8 McMullan R., Jeffrey G.A. (1959) Hydrates of the tetra nbutyl and Tetra i-amyl quaternary ammonium salts, J. Chem. Phys. 31, 5, 1231-1234. https://doi.org/10.1063/1.1730574.

9 Dyadin Y.A., Udachin K.A. (1984) Clathrate formation in water-peralkylonium salts systems, in: Clathrate compounds, molecular inclusion phenomena, and cyclodextrins, The Springer Link, pp. 61-72. https://doi.org/10.1007/978-94009-5376-5 4.

10 Dyadin Y.A., Udachin K.A., Bogatyryova S.V., Zhurko F. V., Mironov Y.I. (1988) Cubic structure II double clathrate hydrates with tetra (n-propyl) ammonium fluoride, J. Incl. Phen. 6, 6, 565-575. https://doi.org/10.1007/BF00656337.

11 Sloan E.D. Jr, Koh C.A. (2007) Clathrate hydrates of natural gases, CRC Press, Boca Raton, FL.

12 Gaponenko L.A., Solodovnikov S.F., Dyadin Y.A., Aladko L. S., Polyanskaya T.M. (1984) Crystallographic study of tetran-butylammonium bromide polyhydrates, J. Struct. Chem. 25, 1, 157-159. https://doi.org/10.1007\%2FBF00808575.

13 Lipkowski J., Komarov V.Y., Rodionova T.V., Dyadin Y.A., Aladko L.S. (2002) The structure of tetrabutylammonium bromide hydrate (C4H9) $4 \mathrm{NBr} 21 / 3 \mathrm{H} 2 \mathrm{O}$, J. Supramol. Chem. 2, 4-5, 435-439. https://doi.org/10.1016/S14727862(03)00054-6.

14 Shimada W., Ebinuma T., Oyama H., Kamata Y., Takeya S., Uchida T., Nagao J., Narita H. (2003) Separation of gas molecule using tetra-n-butyl ammonium bromide semiclathrate hydrate crystals, Jpn. J. Appl. Phys. 42, 2A, L129. https://doi.org/10.1143/JJAP.42.L129/meta.

15 Mohammadi A., Manteghian M., Mohammadi A.H. (2013) Dissociation data of semiclathrate hydrates for the systems of tetra-n-butylammonium fluoride $(\mathrm{TBAF})+$ methane + water, $\mathrm{TBAF}+$ carbon dioxide + water, and TBAF + nitrogen + water, J. Chem. Eng. Data 58, 12, 3545-3550. https://doi. org $/ 10.1021 /$ je4008519.

16 Li X.S., Xu C.G., Chen Z.Y., Wu H.J. (2010) Tetra-n-butyl ammonium bromide semi-clathrate hydrate process for postcombustion capture of carbon dioxide in the presence of dodecyl trimethyl ammonium chloride, Energy 35, 9, 39023908. https://doi.org/10.1016/j.energy.2010.06.009. 
17 Sun Z.G., Sun L. (2010) Equilibrium conditions of semiclathrate hydrate dissociation for methane + tetra-n-butyl ammonium bromide, J. Chem. Eng. Data 55, 9, 3538-3541. https://doi.org/10.1021/je100183s.

18 Jin Y., Kida M., Nagao J. (2012) Phase equilibrium conditions for clathrate hydrates of tetra-n-butylammonium bromide (TBAB) and xenon, J. Chem. Eng. Data 57, 6, 1829-1833. https://doi.org/10.1021/je300299b.

19 Rodionova T.V., Komarov V.Y., Villevald G.V., Karpova T. D., Kuratieva N.V., Manakov A.Y. (2013) Calorimetric and structural studies of tetrabutylammonium bromide ionic clathrate hydrates, J. Phys. Chem. 117, 36, 10677-10685. https://doi.org/10.1021/jp406082z.

20 Oyama H., Shimada W., Ebinuma T., Kamata Y., Takeysa S., Uchida T., Nagao J., Narita H. (2005) Phase diagram, latent heat, and specific heat of TBAB semi clathrate hydrate crystals, Fluid Phase Equilib. 234, 1-2, 131-135. https://doi. org/10.1016/j.fluid.2005.06.005.

21 Shimada W., Shiro M., Kondo H., Takeya S., Oyama H., Ebinuma T., Narita H. (2005) Tetra-n-butylammonium bromide-water (1/38), Acta Crystallogr. Sect. C: Cryst. Struct. Commun. 61, 2, 65-66. https://doi.org/10.1107/ S0108270104032743.

22 Suwinska K., Lipkowski J.S., Dyadin Y.A., Komarov V.Y., Terekhova I.S., Rodionova T.V., Manakov A.Y. (2006) Clathrate formation in the water-tetraisoamylammonium propionate system: $\mathrm{X}$-ray structural analysis of the clathrate hydrate $\left(\mathrm{i}-\mathrm{C}_{5} \mathrm{H}_{11}\right) 4 \mathrm{NC}_{2} \mathrm{H}_{5} \mathrm{CO}_{2} 36 \mathrm{H}_{2} \mathrm{O}, \quad J$. Incl. Phenom. Macrocyclic Chem. 56, 3, 331-335. https://doi.org/ 10.1007/s10847-006-9102-5.

23 Li D.L., Du J.W., Fan S.S., Liang D.Q., Li X.S., Huang N.S. (2007) Clathrate dissociation conditions for methane + tetra-nbutyl ammonium bromide (TBAB) + water, J. Chem. Eng. Data 52, 5, 1916-1918. https://doi.org/10.1021/je700229e.

24 Arjmandi M., Chapoy A., Tohidi B. (2007) Equilibrium data of hydrogen, methane, nitrogen, carbon dioxide, and natural gas in semi-clathrate hydrates of tetrabutylammonium bromide, J. Chem. Eng. Data 52, 6, 2153-2158. https://doi.org/ 10.1021/je700144p.

25 Mohammadi A.H., Richon D. (2010) Phase equilibria of semi-clathrate hydrates of tetra-n-butylammonium bromide + hydrogen sulfide and tetra-n-butylammonium bromide + methane, J. Chem. Eng. Data 55, 2, 982-984. https://doi. org $/ 10.1021 /$ je9004257.

26 Gholinezhad J., Chapoy A., Tohidi B. (2011 July) Thermodynamic stability and self-preservation properties of semi-clathrates in the methane + tetra-n-butyl ammonium bromide + water system, in: Proceedings of the 7th International Conference on Gas Hydrates, 17-21 July 2011, Edinburgh, United Kingdom, pp. 17-21.

27 Lee S., Park S., Lee Y., Lee J., Lee H., Seo Y. (2011) Guest gas enculturation in semiclathrates of tetra-n-butylammonium bromide: Stability condition and spectroscopic analysis, Langmuir 27, 17, 10597-10603. https://doi.org/10.1021/ la202143t.

28 Mohammadi A.H., Eslamimanesh A., Belandria V., Richon D. (2011) Phase equilibria of semiclathrate hydrates of $\mathrm{CO}_{2}, \mathrm{~N}_{2}$, $\mathrm{CH}_{4}$, or $\mathrm{H}_{2}+$ tetra-n-butylammonium bromide aqueous solution, J. Chem. Eng. Data 56, 10, 3855-3865. https://doi.org/ $10.1021 /$ je2005159.

29 Liao Z., Guo X., Zhao Y., Wang Y., Sun Q., Liu A., Sun C., Chen G. (2013) Experimental and modeling study on phase equilibria of semiclathrate hydrates of tetra-n-butyl ammonium bromide $+\mathrm{CH}_{4}, \mathrm{CO}_{2}, \mathrm{~N}_{2}$, or gas mixtures, Ind. Eng. Chem. Res. 52, 51, 18440-18446. https://doi.org/ 10.1021/ie402903m.

30 Chen G.J., Guo T.M. (1996) Thermodynamic modeling of hydrate formation based on new concepts, Fluid Phase Equilib. 122, 1-2, 43-65. https://doi.org/10.1016/0378-3812 (96)03032-4.

31 Chen G.J., Guo T.M. (1998) A new approach to gas hydrate modelling, Chem. Eng. J. 71, 2, 145-151. https://doi.org/ 10.1016/S1385-8947(98)00126-0.

32 Roosta H., Khosharay S., Varaminian F. (2013) Experimental study of methane hydrate formation kinetics with or without additives and modeling based on chemical affinity, Energy Convers. Manage. 76, 499-505. https://doi.org/ 10.1016/j.enconman.2013.05.024.

33 Sangwai J.S., Oellrich L. (2014) Phase equilibrium of semiclathrate hydrates of methane in aqueous solutions of tetra-n-butyl ammonium bromide (TBAB) and TBAB$\mathrm{NaCl}$, Fluid Phase Equilib. 367, 95-102. https://doi.org/ 10.1016/j.fluid.2014.01.036.

34 Mech D., Pandey G., Sangwai J.S. (2015) Effect of $\mathrm{NaCl}$, methanol and ethylene glycol on the phase equilibrium of methane hydrate in aqueous solutions of tetrahydrofuran (THF) and tetra-n-butyl ammonium bromide (TBAB), Fluid Phase Equilib. 402, 9-17. https://doi.org/10.1016/j. fluid.2015.05.030.

35 Najibi H., Momeni K., Sadeghi M.T. (2015) Theoretical and experimental study of phase equilibrium of semi-clathrate hydrates of methane + tetra-n-butyl-ammonium bromide aqueous solution, J. Nat. Gas Sci. Eng. 27, 1771-1779. https://doi.org/10.1016/j.jngse.2015.11.002.

36 van derWaals J.H., Platteeuw J.C. (1958) Clathrate solutions, in: Adv Chem Phys, JohnWiley \& Sons. https://doi. org/10.1002/9780470143483.ch1.

37 Verrett J., Renault-Crispo J.S., Servio P. (2015) Phase equilibria, solubility and modeling study of $\mathrm{CO}_{2} / \mathrm{CH}_{4}+$ tetra-n-butylammonium bromide aqueous semi-clathrate systems, Fluid Phase Equilib. 388, 160-168. https://doi. org/10.1016/j.fluid.2014.12.045.

38 Long X., Wang Y., Lang X., Fan S., Chen J. (2016) Hydrate equilibrium measurements for $\mathrm{CH}_{4}, \mathrm{CO}_{2}$, and $\mathrm{CH}_{4}+\mathrm{CO}_{2}$ in the presence of tetra-n-butyl ammonium bromide, J. Chem. Eng. Data 61, 11, 3897-3901. https://doi.org/10.1021/acs. jced.6b00641.

39 Eslamimanesh A., Mohammadi A.H., Richon D. (2012) Thermodynamic modeling of phase equilibria of semiclathrate hydrates of $\mathrm{CO}_{2}, \mathrm{CH}_{4}$, or $\mathrm{N}_{2}+$ tetra-nbutylammonium bromide aqueous solution, Chem. Eng. Sci. 81, 319-328. https://doi.org/10.1016/j.ces.2012.07. 0006.

40 Joshi A., Mekala P., Sangwai J.S. (2012) Modeling phase equilibria of semiclathrate hydrates of $\mathrm{CH}_{4}, \mathrm{CO}_{2}$ and $\mathrm{N}_{2}$ in aqueous solution of tetra-n-butyl ammonium bromide, $J$. Nat. Gas Chem. 21, 4, 459-465. https://doi.org/10.1016/ S1003-9953(11)60391-5.

41 Baghban A., Ahmadi M.A., Pouladi B., Amanna B. (2015) Phase equilibrium modeling of semi-clathrate hydrates of seven commonly gases in the presence of TBAB ionic liquid promoter based on a low parameter connectionist technique, J. Supercrit. Fluids 101, 184-192. https://doi.org/10.1016/ j.supflu.2015.03.004. 
42 Shi L.L., Liang D.Q. (2015) Thermodynamic model of phase equilibria of tetrabutylammonium halide (fluoride, chloride, or bromide) plus methane or carbon dioxide semiclathrate hydrates, Fluid Phase Equilib. 386, 149-154. https://doi. org/10.1016/j.fluid.2014.12.004.

43 Avula V.R., Gardas R.L., Sangwai J.S. (2016) A robust model for the phase stability of clathrate hydrate of methane in an aqueous system of $\mathrm{TBAB}, \mathrm{TBAB}+\mathrm{NaCl}$ and $\mathrm{THF}$ suitable for storage and transportation of natural gas, J. Nat. Gas Sci. Eng. 33, 509-517. https://doi.org/10.1016/j. jngse.2016.05.051.

44 Ma Q.L., Qi J.L., Chen G.J., Sun C.Y. (2016) Modeling study on phase equilibria of semiclathrate hydrates of pure gases and gas mixtures in aqueous solutions of TBAB and TBAF, Fluid Phase Equilib. 430, 178-187. https://doi.org/ 10.1016/j.fluid.2016.10.001.

45 Mesbah M., Soroush E., Rezakazemi M. (2019) Modeling dissociation pressure of semi-clathrate hydrate systems containing $\mathrm{CO}_{2}, \mathrm{CH}_{4}, \mathrm{~N}_{2}$, and $\mathrm{H}_{2} \mathrm{~S}$ in the presence of tetran-butyl ammonium bromide, J. Non-Equilib. Thermodyn. 44, 1, 15-28. https://doi.org/10.1515/jnet-2018-0015.

46 Parhizgar H., Javanmardi J., Mohammadi A.H., Moshfeghian M., Parvasi P. (2018) A thermodynamic framework for modeling semiclathrate hydrate phase stability conditions in gas + tetra-n-butyl ammonium halide aqueous solution system, Asia-Pac. J. Chem. Eng. 13, 3, 2199. https://doi. org/10.1002/apj.2199.

47 Mesbah M., Galledari S.A., Soroush E., Momeni M. (2019) Modeling phase behavior of semi-clathrate hydrates of $\mathrm{CO}_{2}$, $\mathrm{CH}_{4}$, and $\mathrm{N}_{2}$ in aqueous solution of tetra-n-butyl ammonium fluoride, J. Non-Equilib. Thermodyn. 44, 2, 155-167. https://doi.org/10.1515/jnet-2018-0079.

48 Javanmardi J., Babaee S., Eslamimanesh A., Mohammadi A.H. (2012) Experimental measurements and predictions of gas hydrate dissociation conditions in the presence of methanol and ethane-1, 2-diol aqueous solutions, J. Chem. Eng. Data 57, 5, 1474-1479. https://doi.org/10.1021/ je2013846.
49 Rasoolzadeh A., Javanmardi J., Eslamimanesh A., Mohammadi A.H. (2016) Experimental study and modeling of methane hydrate formation induction time in the presence of ionic liquids, J. Mol. Liq. 221, 149-155. https://doi.org/ 10.1016/j.molliq.2016.05.016.

50 Ghaedi H., Javanmardi J., Rasoolzadeh A., Mohammadi A. H. (2018) Experimental study and thermodynamic modeling of methane hydrate dissociation conditions in the simultaneous presence of $\mathrm{BMIM}-\mathrm{BF}_{4}$ and ethanol in aqueous solution, J. Chem. Eng. Data 63, 5, 1724-1732. https://doi. org/10.1021/acs.jced.8b00046.

51 Rasoolzadeh A., Javanmardi J., Mohammadi A.H. (2019) An

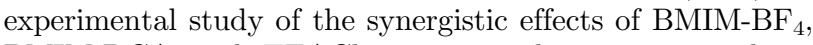
BMIM-DCA and TEACl aqueous solutions on methane hydrate formation, Pet. Sci. 16, 2, 409-416. https://doi.org/ 10.1007/s12182-019-0302-1.

52 Mehrabi K., Javanmardi J., Rasoolzadeh A., Mohammadi A. H. (2021) Effects of diethanolamine and ethylene glycol+ diethanolamine aqueous solutions on methane hydrate stability conditions: Experimental measurements and thermodynamic modeling, J. Mol. Liq. 328, 115472. https://doi. org/10.1016/j.molliq.2021.115472.

53 Peng D.Y., Robinson D.B. (1976) A new two-constant equation of state, Ind. Eng. Chem. Fundam. 15, 1, 59-64. https://doi.org/10.1021/i160057a011.

54 Poling B.E., Thomson G.H., Friend D.G., Rowley R.L., Wilding W.V., Perry R.H., Green D.W. (2008) Chemical Engineers Handbook, The McGraw-Hill Companies.

55 Sfaxi I.B.A., Durand I., Lugo R., Mohammadi A.H., Richon D. (2014) Hydrate phase equilibria of $\mathrm{CO}_{2}+\mathrm{N}_{2}+$ aqueous solution of THF, TBAB or TBAF system, Int. J. Greenhouse Gas Control 26, 185-192. https://doi.org/10.1016/j.ijggc. 2014.04.013.

56 Amid M., Zaferani S.P.G., Amooey A.A. (2021) A compare review about equilibrium conditions of semi-clathrate hydrate: experimental measurements visions and thermodynamic modeling aspects, J. Incl. Phenom. Macrocyclic Chem. 100, 109129. https://doi.org/10.1007/s10847-021-01062-w. 